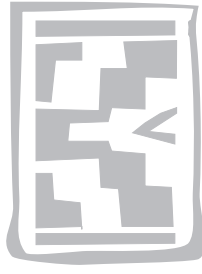

\title{
Naturally acquired antibodies to Bacillus anthracis protective antigen in vultures of southern Africa
}

\author{
P.C.B. TURNBULL ${ }^{1 *}$, M. DIEKMANN², J.W. KILIAN ${ }^{3}$, W. VERSFELD ${ }^{3}$, V. DE VOS ${ }^{4}$, \\ L. ARNTZEN ${ }^{5}$, K. WOLTER ${ }^{6}$, P. BARTELS ${ }^{7}$ and A. KOTZE 7,8
}

\begin{abstract}
TURNBULL, P.C.B., DIEKMANN, M., KILIAN, J.W., VERSFELD, W., DE VOS, V., ARNTZEN, L., WOLTER, K., BARTELS, P. \& KOTZE, A. 2008. Naturally acquired antibodies to Bacillus anthracis protective antigen in vultures of southern Africa. Onderstepoort Journal of Veterinary Research, 75:95-102

Sera from 19 wild caught vultures in northern Namibia and 15 (12 wild caught and three captive bred but with minimal histories) in North West Province, South Africa, were examined by an enzyme-linked immunosorbent assay (ELISA) for antibodies to the Bacillus anthracis toxin protective antigen (PA). As assessed from the baseline established with a control group of ten captive reared vultures with well-documented histories, elevated titres were found in 12 of the $19(63 \%)$ wild caught Namibian birds as compared with none of the 15 South African ones. There was a highly significant difference between the Namibian group as a whole and the other groups $(P<0.001)$ and no significant difference between the South African and control groups $(P>0.05)$. Numbers in the Namibian group were too small to determine any significances in species-, sex- or age-related differences within the raw data showing elevated titres in four out of six Cape Vultures, Gyps coprotheres, six out of ten Whitebacked Vultures, Gyps africanus, and one out of three Lappet-faced Vultures, Aegypius tracheliotus, or in five of six males versus three of seven females, and ten of 15 adults versus one of four juveniles. The results are in line with the available data on the incidence of anthrax in northern Namibia and South Africa and the likely contact of the vultures tested with anthrax carcasses. It is not known whether elevated titre indicates infection per se in vultures or absorption of incompletely digested epitopes of the toxin or both. The results are discussed in relation to distances travelled by vultures as determined by new tracking techniques, how serology can reveal anthrax activity in an area and the issue of the role of vultures in transmission of anthrax.
\end{abstract}

Keywords: Antibodies, anthrax, Bacillus anthracis, serology, vultures

* Author to whom correspondence is to be directed. E-mail: peterturnbull@tesco.net

1 Arjemptur Technology Ltd, Bldg 227, Science Park, Down, SP4 OJQ, United Kingdom

2 Rare and Endangered Species Trust, Otjiwarongo, Namibia

3 Etosha Ecological Institute, Okaukuejo, Namibia

4 P.O. Box 14724, Nelspruit, South Africa

5 National Institute for Communicable Diseases, Private Bag X4, Sandringham, 2131 South Africa

6 Vulture Programme, Rhino and Lion Wildlife Conservation NPO, Nyoka Ridge, Magaliesburg, South Africa

7 National Zoological Gardens of SA, Pretoria, South Africa

8 University of the Free State, Bloemfontein, South Africa

Accepted for publication date 2008-Editor

\section{INTRODUCTION}

It has been a long-held suspicion that vultures transmit anthrax over long distances (Bullock 1956; Ebedes 1976). U. de V. Pienaar, biologist at the Kruger National Park (KNP) in the 1960s, held the conviction that water polluted by vultures bathing in their hundreds rendered waterhole water an important source of anthrax in the KNP (Pienaar 1961, 1967) and $V$. de Vos, long-time veterinarian and scientific adviser in the KNP, has continued to support the theory that vultures contribute to the transmission of anthrax by contaminating water holes (De Vos 1990; De Vos \& Bryden 1996; Hugh-Jones \& De Vos 
2002; De Vos \& Turnbull 2004) referring to this as "the water cycle" (De Vos \& Bryden 1996). On the other hand, De Vos (De Vos 1990; Hugh-Jones \& De Vos 2002; De Vos \& Turnbull 2004) supports the belief of Houston \& Cooper (1975) that by rapidly consuming the bacilli-laden soft tissues of the anthrax victim before the anthrax bacilli have a chance to sporulate (the vegetative bacilli are destroyed in the vultures' digestive tracts), vultures minimize residual contamination and therefore have a role in curtailing spread of the disease.

Houston \& Cooper (1975) considered that for a vulture to play a role in disease transmission, the agent of the disease must (a) cause clinical or subclinical infection and be passed out in the bird's secretions or excretions, or be spread by vectors, or (b) be transmitted mechanically on the bird's feet or feathers, or (c) be regurgitated with pellets from the crop, or (d) pass through the vulture's alimentary tract and be voided in the faeces. They felt too little was known about diseases of vultures to be able to assess (a). While they considered that (b) can undoubtedly occur, they felt the most important potential method of disease dissemination would come from (c) and (d). They fed anthrax vaccine spores to White-backed Vultures and recovered them from the faeces but failed to recover what they implied were vegetative Bacillus anthracis cells (although the culture details are not given and feeding the spore form of $B$. anthracis alone, is not truly representative of what occurs in the field). Lindeque \& Turnbull (1994) found that anthrax spores could be detected at low concentrations in the faeces of vultures associated with anthrax carcasses.

Vultures are well adapted to scavenging carcasses of animals that have died from diseases of microbiological origin. As reviewed by Ohishi, Sakaguchi, Riemann, Behymer \& Hurvell (1979), turkey vultures, Cathartes aura, have been shown to be highly resistant to botulinum toxins (Kalmbach 1939; Pates 1967, cited by Ohishi et al. 1979). This has been attributed, at least in part, to a resistance in the parasynaptic nerve endings (Cohen 1970, cited by Ohishi et al. 1979). Ohishi et al. (1979) themselves, using passive haemagglutination and serum neutralization tests, observed naturally occurring antibodies to all the botulinum toxins in 18 of 20 turkey vultures and suggested that this might contribute to the resistance of these birds to botulism. In anthrax-endemic areas where large numbers of vultures feed on the carcasses of anthrax victims, wildlife workers report finding a dead vulture on the rare occasion but, generally, the cause of death is not investigated. One of the authors of the present article (De Vos) recalls confirming death from anthrax in one vulture by blood smear examination and subsequent culture of $B$. anthracis from its blood. It was, however, the only bird found dead out of a very large number feeding on carcasses during several large outbreaks of the disease in the KNP. It seems clear, therefore, that fatal illness from anthrax in vultures is rare. However, there is no information on whether they suffer clinical or subclinical infection. Houston \& Cooper (1975) considered that, even if they do, this was unlikely to play a major role in the spread of anthrax in the herbivorous species predominantly affected by the disease. Nevertheless, the possible effect of any morbidity that does occur on the population dynamics of the vultures themselves remains unknown.

The purpose of this study at the outset was to look for serological evidence of infection occurring in vultures consuming the carcasses of animals that had died of anthrax.

\section{MATERIALS AND METHODS}

Three groups of vultures were involved. The sera from Groups 1 and 2 were from the collection at the Rare and Endangered Species Trust (REST), Otjiwarongo, Namibia.

Group 1 comprised 19 wild caught vultures consisting of six Cape Vultures, Gyps coprotheres, ten White-backed Vultures, Gyps africanus, and three Lappet-faced Vultures, Aegypius tracheliotus. These derived from groups which generally circulate over the area just south of the Etosha National Park in Namibia and probably over the park itself. Although their precise ages were not known at the time of the investigation, four of them were immature or juveniles. Seven were females, six were males and the sex of the remainder was undetermined. Two of the birds were bled in March 2004, two in November 2004 and the remainder in January and February 2005.

Group 2 consisted of 15 Cape Vultures initially housed at the De Wildt Cheetah and Wildlife Trust, North West Province, South Africa. They had been transferred to REST in two shipments in 2003 and 2004, respectively, and held in a release aviary until October 2005, when they were bled and released. Their capture dates from the wild were not available, but two had been captive bred since hatching in May 2000 and one since hatching in May 2003. Two of the birds were still immature at time of bleeding. The group was made up of eight females and seven males. 
Group 3 was a control group with well defined histories. These were captive-reared vultures comprising six Cape Vultures and one White-backed Vulture, housed at the National Zoological Gardens of South Africa, Pretoria, and three Cape Vultures hand reared at the Rhino and Lion Wildlife Conservation Nonprofit Organisation, Nyoka Ridge, North West Province, South Africa. Five were juveniles (maximum 7 months old), three were females, three males and the remainder sex undetermined. Blood was collected from these in January 2007.

The sera were tested for antibodies to the protective antigen (PA) of $B$. anthracis by the inhibition enzymelinked immunosorbent assay (ELISA) used in previous studies (Turnbull, Broster, Carman, Manchee \& Melling 1986; Turnbull, Carman, Lindeque, Joubert, Huebschle \& Snoeyenbos 1989; Turnbull, Doganay, Lindeque, Aygen \& McLaughlin 1992; Turnbull, Tindall, Coetzee, Conradie, Bull, Lindeque \& Huebschle 2004). ELISA plates with 96 wells (Nunc MaxiSorp, Nunc A/S, Roskilde, Denmark) were coated by adding $50 \mu \ell$ per well of a $7.5 \mu \mathrm{g} / \mathrm{ml}$ solution of PA (a lyophilized preparation kindly supplied by Dr Stephen Leppla, National Institutes of Health, Bethesda, Maryland, USA in 1998) in carbonate coating buffer ( $\mathrm{pH}$ 9.4).

The plates were held in a refrigerator overnight and washed with buffered saline (phosphate or tris) containing $0.5 \mathrm{~m} / \mathrm{l} \ell$ Tween-20 (BST). Then $150 \mu \ell$ of a $10 \%(\mathrm{w} / \mathrm{v})$ solution of dehydrated skim milk in phosphate buffered saline (no Tween) was added to each well and the plates left at room temperature for 30-60 min. After washing with BST, two rows of wells were used for each test. In the first row, $50 \mu l$ BST containing $10 \%(\mathrm{w} / \mathrm{v})$ skim milk (BSTM) were dispensed into each well with an extra $25 \mu \ell$ in the first well. The wells in the second row (inhibition line of wells) each received $50 \mu \ell$ of BSTM containing $7.5 \mu \mathrm{g} / \mathrm{ml}$ PA. Again an extra $25 \mu \ell$ was added to the first well. To the first wells of each row were added $25 \mu \ell$ of the test serum, pre-diluted where necessary, and serial doubling dilutions were made to the ends of the rows. The plates were incubated at $37^{\circ} \mathrm{C}$ for approximately $1 \mathrm{~h}$ before washing, addition of conjugate that was made up in BSTM and, after further incubation and washing, subsequent addition of substrate ABTS (Kirkegaard \& Perry Laboratories, Maryland, USA). The reactions were read after a $40 \mathrm{~min}$ incubation period at $37^{\circ} \mathrm{C}$.

In the absence of antiserum to vulture immunoglobulins, rabbit anti-chicken IgY-peroxidase conjugate (Code A9046, Sigma, Saint Louis, MO, USA) and, to confirm the results with a number of the sera, Pro- tein A-peroxidase conjugate (Code P8651, Sigma, Saint Louis, MO, USA) were used to detect the captured vulture immunoglobulins. The anti-chicken conjugate was used at a dilution 1:750 in BSTM and the Protein-A conjugate at 1:250 with $50 \mu \ell$ per well.

The tests on Groups 1 and 2 sera were carried out in the Etosha Ecological Institute, Okaukuejo, Namibia in November 2005. The Group 3 tests were done at the National Institute for Communicable Diseases, Sandringham South Africa, in January 2007.

\section{RESULTS}

Taking the three groups as a whole, the means and standard deviations of the ELISA readings (expressed as $\log _{2}$ ) were 7.63 (SD 1.35), 4.81 (SD 1.42) and 5.25 (SD 1.12), respectively for Group 1, the wild caught birds in northern Namibia, Group 2, the De Wildt birds in South Africa and Group 3, the captive reared controls. This indicates a highly significant difference between Group 1 vultures and both other groups $(P<0.001$ by Student's unpaired t-test). There was no significant difference between the De Wildt and control groups $(P>0.05)$

At the outset, when Groups 1 and 2 sera were tested in November 2005, there were no available positive and negative controls and test controls depended on serology being carried out at the same time on other species (human, lion and rhinoceros) for which controls were available from previous studies (Turnbull et al. 1992, 2004). At that time, by the criteria for a positive normally used (three consecutive pairs of wells showing $a \geq 20 \%$ difference between test and inhibition lines), only one indisputably unreactive serum was found. This was not one of the three birds that had been captive bred and reared. It was therefore necessary to establish a baseline test reading and this subsequently became possible in January 2007 with the Group 3 vultures. It then became clear that 12 of the 19 (63\%) wild caught Namibian (Group 1) vultures had raised antibody titres to $P A$, as compared with none of the 15 birds from the De Wildt sanctuary in South Africa.

Numbers in the Namibian group (Group 1) were too small to determine any significances in species-, sex- or age-related differences within the raw data showing elevated titres in four of the six Cape Griffons, six of the ten White-backed Vultures and one of the three Lappet-faced Vultures, or in five of six males versus three of seven females, and ten of 15 adults versus one of four juveniles. 


\section{DISCUSSION}

\section{Exposure to anthrax}

The absence of elevated titres in the South African vultures as compared with the Namibian birds appears to support the evidence from the tracking data (Fig. 1) that transects of areas patrolled by vultures in southern Africa generally do not exceed about $300 \mathrm{~km}$ (although it is recognized that, on occasion, they can fly far greater distances). In the case of the Group 1 birds, such patrol areas take in sites of potentially high year-round incidences of anthrax in northern Namibia. In the farms south of Etosha, although cattle are vaccinated, anthrax certainly occurs in other species. Thirty cases of anthrax in goats, of which 15 were confirmed in the Outjo area, 15 confirmed cases in oryx, Oryx gazella, and two bovine cases (one confirmed) in the Otjiwarongo

FIG. 1 Representation of areas covered by six vultures as mapped by satellite telemetry, 2004-2005

CV Cape Vulture

WBCV Cape Vulture/Whitebacked cross

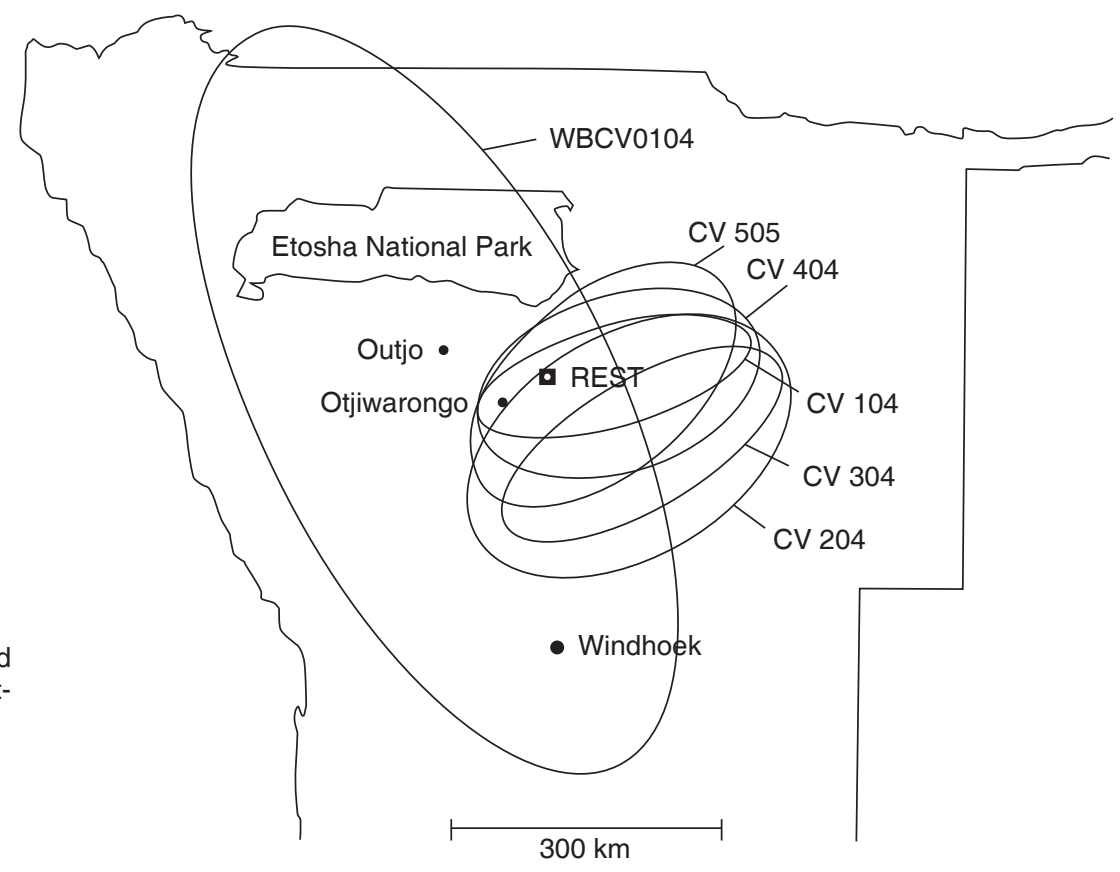

FIG. 2 Incidents of anthrax in wildlife and livestock in South Africa, 19952005. Geographical locations of the incidents listed in Table 1

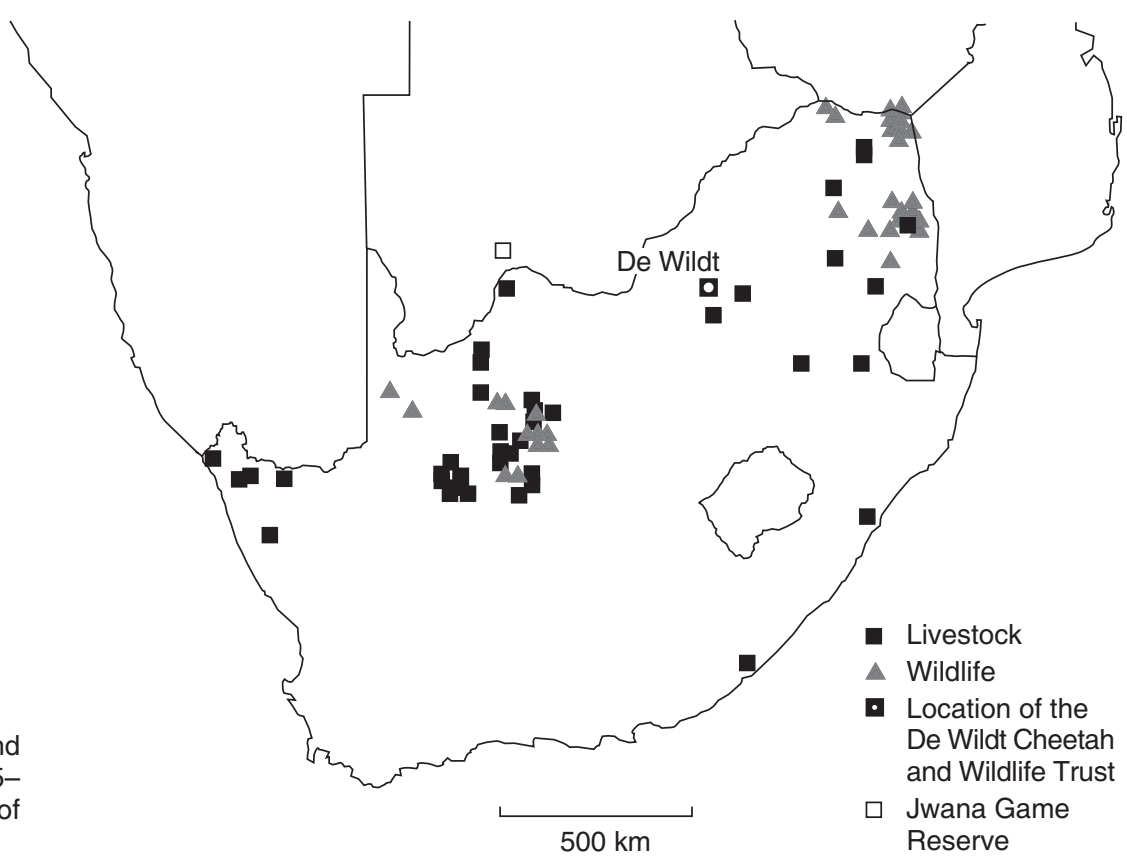


TABLE 1 Reported incidents of anthrax in wildlife (WL) and livestock (LS) in South Africa, 1995-2005, by month, district and numbers of cases $^{\mathrm{a}}$

\begin{tabular}{|c|c|c|c|c|c|c|c|c|c|c|c|c|c|}
\hline District & WL/LS & $\mathbf{J}$ & $\mathbf{F}$ & M & A & M & J & J & A & s & 0 & $\mathbf{N}$ & D \\
\hline Kimberley & $\begin{array}{l}\text { WL } \\
\text { LS }\end{array}$ & $\begin{array}{l}2 \\
2\end{array}$ & 3 & $\begin{array}{l}3 \\
4\end{array}$ & $\begin{array}{l}1 \\
3\end{array}$ & 8 & $\begin{array}{l}1 \\
2\end{array}$ & $\begin{array}{l}2 \\
5\end{array}$ & $\begin{array}{l}1 \\
1\end{array}$ & & 1 & 1 & 2 \\
\hline Northeast & $\begin{array}{l}\text { WL } \\
\text { LS }\end{array}$ & 2 & 2 & 3 & & 0 & 1 & $\begin{array}{l}1 \\
1\end{array}$ & 3 & 3 & $\begin{array}{l}3 \\
1\end{array}$ & & 1 \\
\hline All others & $\begin{array}{l}\text { WL } \\
\text { LS }\end{array}$ & 3 & & 2 & 2 & $\begin{array}{l}1 \\
2\end{array}$ & 1 & 2 & $\begin{array}{l}2 \\
3\end{array}$ & $\begin{array}{l}2 \\
3\end{array}$ & $\begin{array}{l}1 \\
2\end{array}$ & 2 & $\begin{array}{l}1 \\
1\end{array}$ \\
\hline Total incidents & & 9 & 5 & 12 & 6 & 11 & 5 & 11 & 10 & 8 & 8 & 3 & 5 \\
\hline $1-3$ cases & $\begin{array}{l}\text { WL } \\
\text { LS }\end{array}$ & $\begin{array}{l}6 \\
2\end{array}$ & $\begin{array}{l}2 \\
2\end{array}$ & $\begin{array}{l}5 \\
5\end{array}$ & $\begin{array}{l}1 \\
3\end{array}$ & $\begin{array}{r}0 \\
10\end{array}$ & $\begin{array}{l}1 \\
3\end{array}$ & $\begin{array}{l}3 \\
6\end{array}$ & $\begin{array}{l}6 \\
3\end{array}$ & $\begin{array}{l}5 \\
3\end{array}$ & $\begin{array}{l}5 \\
2\end{array}$ & $\begin{array}{l}3 \\
0\end{array}$ & $\begin{array}{l}4 \\
1\end{array}$ \\
\hline $4-8$ cases & $\begin{array}{l}\text { WL } \\
\text { LS }\end{array}$ & & 1 & $\begin{array}{l}1 \\
1\end{array}$ & & 1 & & & 1 & & & & \\
\hline $9-15$ cases & $\begin{array}{l}\text { WL } \\
\text { LS }\end{array}$ & & & & 1 & & 1 & 2 & & & 1 & & \\
\hline$>15$ cases & $\begin{array}{l}\text { WL } \\
\text { LS }\end{array}$ & $1^{b}$ & & & $1^{c}$ & & & & & & & & \\
\hline
\end{tabular}

a From case data kindly supplied by Dr Grietjie de Klerk, Chief State Veterinarian: Epidemiology, Directorate of Animal Health, Department of Agriculture, Republic of South Africa

b An outbreak affecting 53 eland, Taurotragus oryx, in the Northern Cape Province in January 2001

c An outbreak involving 80 sheep in Lekwa district, April 2002

district in 2004 and further reported cases in wildlife in these districts in 2005 (annual reports of the Ministry of Agriculture, Water and Rural Development, $2004,2005)$ are possibly representative of substantially more cases that are not observed or reported. The Ministry's annual reports further show that anthrax also occurs in livestock in the districts north and northwest of Etosha and the enzootic southeast region of the Etosha National Park itself is easily within the reach of Group 1 vultures.

In contrast, although the principal patrol areas of the De Wildt vultures in South Africa are not known, the majority of the birds are brought in from the Magaliesberg mountain range in the North West and Gauteng provinces. This range lies approximately $500 \mathrm{~km}$ from the areas of South Africa experiencing the highest incidence of anthrax (Fig. 2, Table 1). In addition, there are no records of anthrax in southern Botswana in the annual reports of the Botswana National Laboratory in recent years, and the only known recent occurrence of the disease has been in the wildlife of the Jwana Game Reserve at Jwaneng, also about $500 \mathrm{~km}$ from the Magaliesberg (Fig. 2) where it has been apparent since 2004 (K. Good, personal communication 2006).

It can be seen from Table 1 that the reported incidence of anthrax in South Africa is not high (with seasonality only apparent in the livestock) and the majority of recorded incidents over the 10-year period 1995-2005 involved only small numbers of animals. Even taking account of the probability that wildlife cases were underreported, this further implies a limited likelihood that the De Wildt vultures had frequent, if any, access to anthrax carcasses.

Although numbers were too small to permit any species associated differences in development of antiPA antibodies, or to assess the significance of sex and age differences in the birds showing elevated titres, the higher proportions of males than females, and of adults as compared with juveniles, showing elevated titres are in line with the frequently observed bias towards adulthood and males in cases of anthrax in animals (Clegg, Turnbull, Foggin \& Lindeque 2007). In the case of vultures, the well-established social hierarchy based on arrival times at a carcass, aggression and beak and body sizes (Hertel 1994) may promote such biases.

The initial difficulties experienced over interpreting the Groups 1 and 2 results in November 2005 that led to the need for constituting and testing Group 3 in January 2007, are attributed to 'background noise' from non-specific 'stickiness'. High binding background exhibited by normal sera of some species is well recognised and frequently referred to anecdo- 
tally as a problem when performing the ELISA (OIE 2000; S. Welkos, personal communication 2007) and ELISA shares with many test systems the need to establish the threshold 'signal-to-noise ratio'. Probable sources of background in ELISA were discussed by Pruslin, To, Winston \& Rodman (1991) who observed that each serum they tested had a characteristic background value. In our case, inclusion of the high concentration of milk $(10 \% \mathrm{w} / \mathrm{v}$ milk powder) in the diluent for all stages prior to adding the ABTS substrate was aimed at minimizing nonspecific stickiness. The possibility that the problem lay within the use of the rabbit anti-chicken IgYperoxidase conjugate was ruled out by confirmation of results in repeat tests on a proportion of the sera using Protein A-peroxidase conjugate. Similarly, the possibility that milk was not a suitable blocking agent, was ruled out by showing that replacing milk with foetal calf serum $(5 \% \mathrm{v} / \mathrm{v})$ made no difference. Protective antigen is highly specific for $B$. anthracis; cross-reacting antigens have never been reported and are thereby again ruled out as being the cause of background noise.

\section{Infection or translocation of toxin?}

The ELISA used is based on detection of antibodies to PA. The presence of these antibodies is generally regarded as indicating that non-lethal systemic infection by $B$. anthracis has occurred, although the possibility needs to be borne in mind that elevated titres conceivably could represent antibodies to PA components that are translocated through the gut wall to the blood stream. In the case of botulism, this was the implication of the report of Ohishi et al. (1979) that turkey vultures naturally develop antibodies to botulinum toxins. On the other hand, some years earlier, Pates (1967, cited by Ohishi et al. 1979) failed to demonstrate natural antibodies to botulinum toxins or non-specific detoxifying substances in the blood of this species. Blood from guinea pigs dying of anthrax was found to have approximately $40 \mu \mathrm{g}$ of PA per ml (Turnbull 1990), and the hand-held on-site anthrax diagnostic device, based on detection of PA, has shown that wild animals similarly have high levels of PA at death from anthrax (Burans, Keleher, O'Brien, Hager, Plummer \& Morgan 1996). Scavengers, therefore, do ingest substantial amounts of the toxin as well as the bacterium, $B$. anthracis, when feeding on anthrax carcasses.

The results therefore show that, in a manner somewhat analogous to lions (Turnbull et al. 1992), serology in vultures can serve as an indicator of anthrax activity, albeit over a wider area than is the case with lions. Unfortunately, in that it is not possible to say with certainty whether elevated titre indicates infection per se in vultures, as opposed to absorption of incompletely digested epitopes of the toxin, the findings fail to answer the question as to whether any part of the role of vultures in the anthrax cycle is a result of their becoming infected themselves. Thought needs to be given to how it can be established whether toxin or infection, or both, are responsible for elevated titres.

\section{Vultures and the spread of anthrax}

The answers to further questions on the role of vultures in spreading anthrax remain reliant on surveillance and epidemiological indicators. One such indicator, for example, suggesting that the role of vultures in spreading anthrax is generally minimal is that the REST (Namibian) birds frequent the Waterberg Plateau among other sites and there has been no indication that anthrax occurs on the plateau. Expressed more generally, considering the distances vultures fly, a greater and faster spread of anthrax than actually occurs might be anticipated if they were major carriers (MacAdam 1980). Anthrax spores were not found in a random examination of sediment from the pool at the REST vulture restaurant in September 2006 as might have been expected with vultures frequently encountering anthrax carcasses. Likewise, during the period of the study, anthrax spores could not be detected in sediments examined in November 2005 from a waterhole heavily frequented by vultures during a major epidemic of anthrax 1 year earlier in a wildlife trust in Zimbabwe (Clegg et al. 2007). In an earlier study in the Etosha National Park (Lindeque \& Turnbull 1994), anthrax spores were found in the droppings of nine of 18 vultures in the vicinities of anthrax carcasses but the numbers of spores were invariably low and well below what is normally considered to be a likely infectious dose for a grazing herbivore that might encounter them. Evidence has never been presented that anthrax spores can germinate in the intestinal tracts of animals with subsequent colonization or multiplication by the emerging bacilli. Faeces from a vulture which has fed on an anthrax carcass appear, therefore, to be of low risk in terms of giving rise to infection in other animals but the risk must be presumed to rise substantially at sites, such as artificial water holes, which become literally 'white washed' when large numbers of the birds congregate after feeding extensively on an anthrax carcass, or carcasses in an outbreak situation. 


\section{Actions in the event of an anthrax epizootic}

The roles played by scavengers in transmission of anthrax during large outbreaks is unclear and, in the event of a major outbreak of the disease, wisdom dictates that, if pressures on staff do not permit immediate incineration of the carcasses, an important temporary action is to cover carcasses with canvas or thick plastic to deter access by scavengers and by flies. This will minimize spillage of body fluids onto the ground, maximize destruction of the anthrax organisms by putrefactive processes within the unopened carcass and reduce the chance of scavengers or flies spreading the disease. In the case of vultures, vulture diversions (e.g. diverting them to a specific controlled water hole and decoy carcasses) may be appropriate actions.

It is well recognized that the global population of vultures is in major crisis, particularly in Asia. Their importance within the ecosystem should not be underestimated and care should be taken to ensure that a balanced view is maintained of the part they play in the cycle of anthrax. On the one hand, they admittedly may carry infected blood and gore on their beaks and feathers and spores in their intestines after feeding on an anthrax carcass but, on the other hand, they minimize residual environmental contamination from such carcasses by consuming the bacilli-laden tissues before most of the bacilli have sporulated. In addition, for game managers and farmers, circling vultures have always been, and continue to be, the best signal that deaths have occurred in the field, therefore, enabling prompt action where cases or outbreaks of anthrax are occurring. There is no valid reason to consider culling of vultures as part of anthrax control measures; indeed such action might increase problems associated with both anthrax and other diseases as a result of the infected or toxic carcasses, or parts of carcasses, that would remain unscavenged in their absence.

\section{ACKNOWLEDGEMENTS}

The authors express their sincere gratitude to the De Wildt Cheetah and Wildlife Trust, Brits, South Africa for the availability of the Group 2 sera, and also to the following persons: Dr Gisela Eberle, Central Veterinary Laboratory, Windhoek, Namibia for anthrax incidence data for northern Namibia; Dr Kyle Good, Cheetah Conservation Botswana, Gaborone, Botswana for data on anthrax in Botswana; Dr Mark Jago, Ministry of Environment and Tourism, Windhoek, Namibia for assistance with acquiring the study sera; Dr Grietjie de Klerk, Directorate of Ani- mal Health, Department of Agriculture, South Africa for provision of anthrax incidence data in Table 1; Dr Emily Lane, National Zoological Gardens, Pretoria, for advice in preparation of the manuscript; Ms Jacqueline Rankin and Ms Tracy Rehse, National Zoological Gardens, Pretoria, for supplying the control sera; Dr Ingrid Spitze, Otjiwarongo Veterinary Clinic, Otjiwarongo, Namibia for supplying the test sera; Drs Sue Welkos, Bruce Ivins and Steve Little, US Army Medical Research Institute of Infectious Diseases, Frederick, Maryland and Dr Conrad Quinn, Centers for Disease Control and Prevention, Atlanta, Georgia, USA for advice and references relating to immunological aspects of the study.

\section{REFERENCES}

BULLOCK, D.S. 1956. Vultures as disseminators of anthrax. Auk, 73:283-284.

BuRANS, J., KELEHER, A., O'BRIEN, T., HAGER, A., PLUMMER, A. \& MORGAN, C. 1996. Rapid method for the diagnosis of Bacillus anthracis infection in clinical samples using a hand-held assay. Salisbury Medical Bulletin, 87S:36-37.

CLEGG, S.B., TURNBULL, P.C.B., FOGGIN, C.M. \& LINDEQUE, P.M. 2007. Massive outbreak of anthrax in wildlife in the Malilangwe Wildlife Reserve, Zimbabwe. Veterinary Record, 160: 113-118.

DE VOS, V. 1990. The ecology of anthrax in the Kruger National Park, South Africa. Salisbury Medical Bulletin, 68S:19-23.

DE VOS, V. \& BRYDEN, H.B. 1996. Anthrax in the Kruger National Park: temporal and spatial patterns of disease occurrence. Salisbury Medical Bulletin, 87S:26-30.

DE VOS, V. \& TURNBULL, P.C.B. 2004. Anthrax, in Infectious diseases of livestock, with special reference to Southern Africa, edited by J.A.W. Coetzer \& R.C. Tustin, $2^{\text {nd }}$ ed. Cape Town: Oxford University Press Southern Africa.

EBEDES, H. 1976. Anthrax epizootics in Etosha National Park. Madoqua, 10:99-118.

HERTEL, F. 1994. Diversity in body size and feeding morphology within past and present vulture assemblages. Ecology, 75: 1074-1084.

HOUSTON, D.C. \& COOPER, J.E. 1975. The digestive tract of the Whiteback griffon vulture and its role in disease transmission among wild ungulates. Journal of Wildlife Diseases, 11: 306-313.

HUGH-JONES, M.E. \& DE VOS, V. 2002. Anthrax and wildlife. Revue Scientifique et Technique de l'Office International des Épizooties, 21:359-383.

LINDEQUE, P.M. \& TURNBULL, P.C.B. 1994. Ecology and epidemiology of anthrax in the Etosha National Park, Namibia. Onderstepoort Journal of Veterinary Research, 61:71-83.

MACADAM, I. 1980. Putting anthrax into perspective. The Zimbabwe Rhodesia Science News, 14:38-41.

OHISHI, I., SAKAGUCHI, G., RIEMANN, H., BEHYMER, D. \& HURVELL, B. 1979. Antibodies to Clostridium botulinum toxins in free-living birds and mammals. Journal of Wildlife Diseases, 15:3-9.

OIE 2000. Anthrax, in Manual of standards for diagnostic tests and vaccines. Paris: Office International des Épizooties. 
PIENAAR, U. DE V. 1961. A second outbreak of anthrax amongst game animals in the Kruger National Park (South Africa). Koedoe, 4:4-17.

PIENAAR, U. DE V. 1967. Epidemiology of anthrax in wild animals and the control of anthrax epizootics in the Kruger National Park, South Africa. Federal Proceedings, 26:1496-1502.

PRUSLIN, F.H., TO, S.E., WINSTON, R. \& RODMAN, T.C. 1991. Caveats and suggestions for ELISA. Journal of Immunological Methods, 137:27-35.

TURNBULL, P.C.B. 1990. Terminal bacterial and toxin levels in the blood of guinea pigs dying of anthrax. Salisbury Medical Bulletin, 68S: 53-55.

TURNBULL, P.C.B., BROSTER, M.G., CARMAN, J.A., MANCHEE, R.J. \& MELLING, J. 1986. Development of antibodies to protective antigen and lethal factor components of anthrax toxin in humans and guinea pigs and their relevance to protective immunity. Infection and Immunity, 52:356-363.

TURNBULL, P.C.B., CARMAN, J.A., LINDEQUE, P.M., JOUBERT, F., HUEBSCHLE, O.J.B. \& SNOEYENBOS, G.H. 1989. Further progress in understanding anthrax in the Etosha National Park. Madoqua, 16:93-104.

TURNBULL, P.C.B., DOGANAY, M., LINDEQUE, P.M., AYGEN, B. \& MCLAUGHLIN, J. 1992. Serology and anthrax in humans, livestock and Etosha National Park wildlife. Epidemiology and Infection, 108:299-313.

TURNBULL, P.C.B., TINDALL, B.W., COETZEE, J.D., CONRADIE, C.M., BULL, R.L., LINDEQUE, P.M. \& HUEBSCHLE, O.J.B. 2004. Vaccine-induced protection against anthrax in cheetah (Acinonyx jubatus) and black rhinoceros (Diceros bicornis). Vaccine, 22:3340-3347. 